\title{
A educomunicação e as conexões em uma escola da periferia
}

\author{
Educommunication and connections in a school in the periphery
}

Educomunicación y conexiones en una escuela de la periferia

Recebido: 15/09/2021 | Revisado: 20/09/2021 | Aceito: 25/09/2021 | Publicado: 26/09/2021

\author{
Marcela Cristiane Ribeiro Brito \\ ORCID: https://orcid.org/0000-0002-2491-2106 \\ Instituto Federal de Mato Grosso, Brasil \\ E-mail: marcelacrbrito@gmail.com \\ Ronaldo Eustáquio Feitoza Senra \\ ORCID: https://orcid.org/0000-0003-0801-1970 \\ Instituto Federal de Mato Grosso, Brasil \\ E-mail: ronaldo.senra@svc.ifmt.edu.br \\ Thiago Cury Luiz \\ ORCID: https://orcid.org/0000-0003-1196-8124 \\ Universidade Federal de Mato Grosso, Brasil \\ E-mail: thcluiz@gmail.com
}

\begin{abstract}
Resumo
No contexto da pandemia da Covid-19, com o impedimento das aulas presencias e o imperativo das relações via internet, que este artigo apresenta parte dos resultados da pesquisa "Educomunicação socioambiental - narrativas da periferia", realizada no período de 2020 a 2021, na escola pública estadual de Mato Grosso, na capital Cuiabá. O objetivo foi apresentar o paradigma educomunicação para a Escola Estadual Manoel Cavalcanti Proença, para incentivar e valorizar as produções comunicativas de crianças e adolescentes. As propostas possibilitaram a partilha de conhecimentos e a conexão de saberes entre os que puderam fazer parte do processo. Entre os desafios apontados está a exclusão digital da maioria dos matriculados que estão à margem das aulas no formato virtual. A metodologia foi o estudo de caso, por se tratar de um fenômeno novo na referida unidade de ensino. Ao propor iniciativas que unem a educação com a comunicação, a pesquisa somou resultados exitosos com a participação crítica e reflexiva de estudantes sobre a realidade desafiadora, com os murais educomunicativos, e as mudanças ambientais com a oficina de foto e vídeo, que se estendeu para a exposição do varal de fotos na escola. Apesar das dificuldades com o acesso limitado ao sinal de internet e o impedimento das interações presencias, a pesquisa pôde mostrar que é possível realizar conexões entre as pessoas, com ações educomunicativas em uma escola da periferia de Cuiabá-MT.
\end{abstract}

Palavras-chave: Conexões; Covid-19; Educomunicação; Ensino; Exclusão digital; Pandemia.

\section{Summary}

In the context of the Covid-19 pandemic, with the impediment of in-person classes and the imperative of relationships via the internet, this article presents part of the results of the research "Social and environmental education narratives from the periphery", carried out from 2020 to 2021, in state public school in Mato Grosso, in the capital Cuiabá. The objective was to present the educommunication paradigm to the Manoel Cavalcanti Proença State School, to encourage and value the communicative productions of children and adolescents. The proposals made it possible to share knowledge and connect knowledge between those who could be part of the process. Among the challenges pointed out is the digital exclusion of the majority of those enrolled who are on the margins of classes in the virtual format. The methodology was the case study, as it is a new phenomenon in that teaching unit. By proposing initiatives that unite education with communication, the research added successful results with the critical and reflective participation of students on the challenging reality, with educommunicative murals, and environmental changes with the photo and video workshop, which extended to the exhibition of the photo clothesline at the school. Despite the difficulties with limited access to the internet signal and the impediment of face-to-face interactions, the research was able to show that it is possible to make connections between people, with educommunicative actions in a school on the outskirts of Cuiabá-MT.

Keywords: Connections; Covid-19; Educommunication; Teaching; Digital exclusion.

\section{Resumen}

En el contexto de la pandemia del Covid-19, con el impedimento de las clases presenciales y el imperativo de las relaciones a través de internet, este artículo presenta parte de los resultados de la investigación "Educación social y ambiental - narrativas desde la periferia", realizada de 2020 a 2021, en escuela pública estatal en Mato Grosso, en la capital Cuiabá. El objetivo fue presentar el paradigma de la educomunicación a la Escuela Estatal Manoel Cavalcanti Proença, para incentivar y valorar las producciones comunicativas de niños y adolescentes. Las propuestas 
permitieron compartir conocimientos y conectar conocimientos entre quienes podrían ser parte del proceso. Entre los desafíos señalados está la exclusión digital de la mayoría de los matriculados que se encuentran al margen de las clases en el formato virtual. La metodología fue el estudio de caso, ya que es un fenómeno nuevo en esa unidad didáctica. Al proponer iniciativas que unen educación con comunicación, la investigación sumó resultados exitosos con la participación crítica y reflexiva de los estudiantes sobre la realidad desafiante, con murales educomunicativos, y cambios ambientales con el taller de foto y video, que se extendió a la exhibición del foto tendedero. en la escuela. A pesar de las dificultades con el acceso limitado a la señal de internet y el impedimento de las interacciones cara a cara, la investigación pudo demostrar que es posible hacer conexiones entre personas, con acciones educomunicativas en un colegio de las afueras de Cuiabá-MT.

Palabras clave: Conexiones; Covid-19; Educomunicación; Enseñando; Exclusión digital.

\section{Introdução}

Conexão é uma das palavras mais utilizadas na atualidade, seja a conexão virtual referente aos cabos de internet e ao sinal que chega nos computadores e celulares, seja a conexão entre pessoas, que as relações presenciais nos proporcionavam antes das medidas de restrição. A Pandemia da Covid-19, que teve início em 2020 no Brasil e continua colocando em risco de morte as vidas das pessoas em 2021, trouxe uma série de impedimentos e mudanças de hábitos para conter as contaminações. A educação passou por mudanças na rotina das aulas e com o impedimento dos encontros em sala de aula, uma das alternativas foram as aulas online.

Neste contexto de isolamento social, impedimento das aulas nos espaços físicos da escola, que a pesquisa "Educomunicação socioambiental - narrativas da periferia" se desenvolveu em uma escola da rede pública de Mato Grosso, na capital Cuiabá, entre 2020 e 2021. A Escola Estadual Manoel Cavalcanti Proença, localizada no bairro Tijucal, aceitou o desafio de fazer parte de uma ação pesquisadora em plena pandemia, permitiu a pesquisa acompanhar as aulas na modalidade online, a acompanhar a entrega de material apostilado para as famílias que optaram por este modo de estudo, e permitiu que a educomunicação fosse apresentada para os estudantes, professores, funcionários, mães, pais e responsáveis pelas crianças e adolescentes matriculadas na unidade escolar.

O Núcleo de Comunicação e Educação da Universidade de São Paulo (NEC-USP) define o termo educomunicação como "um campo de ação emergente na interface entre tradicionais campos da educação e da comunicação, apresenta-se hoje como um excelente caminho de renovação de prática sociais que objetivam ampliar as condições de expressão [...]” (Soares, 2011, p.16). Esta definição já vem sendo superada à medida que as pesquisas e ações no campo da educomunicação foram se ampliando e hoje, esta interface se consolidou, sendo a educomunicação um paradigma que direciona ações comunicativas em ambientes abertos de diálogo, em diversos campos de intervenção.

Em julho de 2021, o neologismo (palavra nova) educomunicação passou a fazer parte do Vocabulário Ortográfico da Língua Portuguesa (Volp), pela Academia Brasileira de Letras (ABL), com as seguintes definições:

1. Conjunto de conhecimentos e ações que visam desenvolver ecossistemas comunicativos abertos, democráticos e criativos em espaços culturais, midiáticos e educativos formais (escolares), não formais (desenvolvidos por ONGs) e informais (meios de comunicação voltados para a educação), mediados pelas linguagens e recursos da comunicação, das artes e tecnologias da informação, garantindo-se as condições para a aprendizagem e o exercício prático da liberdade de expressão.

2. Formação e atividade profissional do educomunicador, relacionadas ao estudo e aplicação desses conhecimentos. (Academia Brasileira de Letras, 2021)

Machado (2007, p.03) destaca que a educomunicação atua na formação de agentes em um campo complexo, em uma perspectiva de garantir a autonomia de quem faz parte das ações, seja na educação formal ou não-formal. "O princípio surge com Paulo Freire e é desenvolvido na educomunicação". A Associação Brasileira de Pesquisadores e Profissionais em Educomunicação (ABPEducom) define o termo como "um paradigma orientador de práticas sócio-educativo-comunicacionais 
que têm como meta a criação e fortalecimento de ecossistemas comunicativos abertos e democráticos nos espaços educativos" (ABPEDUCOM, 2020).

Com base nestas definições que a pesquisa apresentou o objetivo de apresentar para todos os envolvidos no processo de ensino-aprendizagem da escola pública da periferia de Cuiabá esta alternativa paradigmática que une a educação e a comunicação de forma democrática, mobilizadora e inclusiva. Tal objetivo se apresentou mais desafiador, uma vez que o processo pesquisador ocorreu durante o início da proliferação do vírus no Brasil, que determinou a suspensão das aulas presencias e o modelo de aulas virtuais passaram a substituir a formação escolarizada.

\section{Metodologia}

Neste artigo, apresentamos parte das observações elencadas ao final de pesquisa no que diz respeito às práticas educomunicativas durante a pandemia e a limitação de acesso à internet pela maioria dos estudantes da referida escola localizada na periferia de Cuiabá-MT. O embasamento metodológico teve como suporte os autores Yin $(2001 ; 2015)$ e Stake (1999) com o estudo de caso. A pedagogia Freiriana e Frenetiana também estão presentes no desenvolver das ações pesquisadoras, e autores na área da educomunicação fazem parte desta experiência.

Entre as ações realizadas na escola de Cuiabá, elenquemos três para a realização das reflexões acerca da participação dos estudantes durante o isolamento social determinado pela pandemia. A pesquisa teve como base a dialogicidade do educador Paulo Freire ao reconhecer a importância do ouvir o educando, e assim aprender com o outro. "O sujeito que se abre ao mundo e aos outros inaugura o seu gesto a relação dialógica em que confirma a como inquietação e curiosidade, como inconclusão em permanente movimento na história (Freire, 2015, p.133). A base das trocas de conhecimento e experiências que ocorrem durante a pesquisa se deram através do diálogo, de possibilitar que a comunicação entre os participantes ocorresse, apesar dos desafios enfrentados no período pandêmico.

Outro educador que caminhou teoricamente nesta pesquisa foi Celèstin Freinet (2010), que defende em suas obras a importante iniciativa do professor em fazer com que a escola não seja somente um espaço físico, mas também espaços de aprendizagem para serem explorados, criados e revistos. Para o docente francês, explorar os espaços físicos, conhecer a redondeza da escola, estar em contato com a comunidade e ver a educação para além dos muros escolares enriquece o processo de ensino-aprendizagem dos aprendizes.

Com base na dialogicidade e na valorização das produções estudantis que a pesquisa propôs a realização de três ações educomunicativas na Escola Estadual Manoel Cavalcanti Proença em setembro e dezembro de 2020 e março de 2021. A primeira ação foi intitulada "Árvore da Esperança", com a montagem de um mural no formato de árvore cujas folhas estavam afixadas as produções dos participantes da ação educomunicativa. Para fazer parte deste trabalho coletivo, os participantes responderam o seguinte questionamento: "O que você espera do pós-pandemia?". As respostas foram enviadas por meio de textos, desenhos, frases e poesias, via internet, por aplicativo de conversação, ou entregue na secretaria da escola presencialmente, respeitando todas as medidas de biossegurança.

A segunda ação também foi realizada no mesmo mural onde estava a "Árvore da Esperança”. A proposta foi que os estudantes do $1^{\circ}$ ano ao $9^{\circ}$ ano do Ensino Fundamental mandassem recados para o ano de 2021. Assim como a primeira experiência realizada, nesta os participantes mandaram as mensagens via aplicativo de conversação de celular ou deixaram na secretaria da escola. Em dezembro, então, o mural foi preenchido com sonhos, desejos e anseios para o ano que se aproximava. Muitos desejos se relacionavam com a vontade de voltar para a escola, o encontro com os amigos e o fim da pandemia da Covid-19.

A terceira iniciativa da pesquisa foi realizada em março de 2021, com dois encontros virtuais com a realização da oficina de foto e vídeo. Nesta ação, a interação ocorreu de forma exclusivamente virtual com formação de grupo de 
conversação por telefone e com encontros em sala virtuais. Esta oficina educomunicativa trouxe a temática ambiental para as produções de vídeos e foto. Durante a oficina com as apresentações dos estudantes, surgiu a proposta da realização de uma exposição das fotos por meio de um varal que ficou exposto, no mês de abril, no espaço da escola destinado à entrega de material apostilado. Quem foi à escola buscar apostila para os estudos, teve a oportunidade de conferir o resultado da oficina online. As fotos dos educandos se basearam no seguinte questionamento: "O que você vê da janela da sua casa sobre o meio ambiente?".

\section{Resultados e Discussão}

Após descrita as três iniciativas, de forma resumida, destacamos como se deu a interação virtual dos estudantes durante o período de pesquisa. O destaque foi o acesso, ou melhor, o não acesso ao sinal de internet. Muitos estudantes deixaram de participar das propostas educomunicativas por não possuir conexão via internet no aparelho de celular, muito menos na residência. Durante a pesquisa, tivemos a oportunidade de dialogar com mães e pais que recorreram ao material apostilado da escola por não conseguirem acompanhar as aulas online oferecidas pela escola. Entre os relatos estava de uma família que possuía três crianças matriculadas em séries diferentes e na casa possuir apenas um aparelho de celular com acesso limitado à internet. O relato foi que seria impossível acompanhar as aulas virtuais com um único aparelho, que a família também utilizava para as demandas do emprego.

No momento de realização das ações educomunicativas, muitos professores da escola destacaram como um dos maiores entraves para reunir as turmas virtuais as dificuldades de conseguir se comunicar com frequência com os estudantes devido à falta de conexão de internet das crianças e jovens. Há casos citados pelas famílias de estudantes que só conseguem participar das aulas remotas quando um dos vizinhos empresta o sinal de Wi-Fi para que o estudante acompanhe as atividades da escola.

Estes relatos que justificam a ausência de participação dos encontros virtuais foram refletidos nos dados levantados pela equipe gestora da escola, durante o ano de 2020. Conforme o levantamento feito pela coordenação pedagógica da escola, entre as 22 turmas do Ensino Fundamental da Escola Estadual Manoel Cavalcanti Proença ( $1^{\circ}$ ano ao $9^{\circ}$ ano), menos de $40 \%$ dos matriculados acompanharam as aulas online. Dos 588 estudantes, menos de 235 conseguiram acompanhar os encontros virtuais, interagir com os colegas e professores durante as aulas e atividades propostas, como por exemplo, as ações educomunicativas.

A realidade da escola de Cuiabá não é muito diferente das demais escolas do Brasil e do mundo. Esta exclusão digital faz parte do relatório conjunto do Fundo das Nações Unidas para a Infância (UNICEF) e da União Internacional de Telecomunicações (ITU), apresentado em dezembro de 2020. Segundo as entidades, dois terços das crianças e dos adolescentes em idade escolar no mundo - ou 1,3 bilhão de meninas e meninos de 3 a 17 anos - não têm conexão à internet em suas casas. Este relatório intitulado "How Many Children and Youth Have Internet Access at Home?", cuja tradução é "Quantas crianças e jovens têm acesso à internet em casa?", contabiliza uma falta de acesso semelhante entre os jovens de 15 a 24 anos, com 759 milhões ou 63\% sem conexão em casa.

Outra pesquisa evidencia a realidade do não acesso à internet, e consequentemente, a interrupção dos estudos por parte das crianças e jovens no Brasil. O documento "Cenário da exclusão escolar no Brasil - Um alerta sobre os impactos da pandemia da COVID-19 na Educação", publicado pela Unicef em abril de 2021 aponta dados que confirmam que aumentou o índice de matriculados sem rotina de estudos. O relatório aponta que em novembro de 2020, mais de 5 milhões de meninas e meninos de 6 a 17 anos não tinham acesso à educação no Brasil, sendo que mais de $40 \%$ eram crianças de 6 a 10 anos, faixa etária em que a educação estava praticamente universalizada antes da pandemia. "Os números são alarmantes e trazem um 
alerta urgente. O País corre o risco de regredir mais de duas décadas no acesso de meninas e meninos à educação" (Bauer, 2021, p. 05).

A realização das propostas da pesquisa na escola teve como desafio chegar até estes estudantes que não possuem acesso à internet ou, quando possuem, é muito limitado. Entre as alternativas apresentadas pelos pesquisadores para incluir os educandos sem internet nas práticas no campo educomunicativo foi dialogar no momento da retirada das apostilas. Uma parte dos que participaram que compuseram do mural na escola deixaram suas produções de textos ou desenhos na secretaria da escola. Para motivar estas participações, foi disponibilizado um espaço com folhas de papel sulfite e canetas para quem desejassem contribuir com produções. Um cartaz também foi afixado para incentivar a participação de pais e estudantes. Esta estratégia foi utilizada tanto na primeira experiência com a "Árvore da Esperança" quanto com a segunda, "Recados para $2021 \%$

Esta iniciativa possibilitou a inclusão desta parcela de pessoas que não recebem informações online e não se comunicam de forma virtual com a escola. Orozco Gómez (2014, p.33) observa que "Os novos participantes na comunicação têm de aprender a ser comunicadores. E isso é um desafio complexo, político, cultural e socioeconômico, mas que começa com a comunicação e a educação". Este desafio de ser comunicador dos próprios discursos se acentua quando a desigualdade social faz parte da cotidianidade de uma parcela considerável da população brasileira, sendo perceptível na escola onde a pesquisa se desenvolveu.

A educomunicação se apresenta como um caminho para que a escola possibilite o protagonismo juvenil, a formação de pessoas críticas e reflexivas, e importante se faz destacar que as ações podem ser realizadas, independente do universo digital. "Educomunicação é essencialmente práxis social, originando um paradigma orientador da gestão de ações em sociedade. Não pode ser reduzida a um capítulo da didática confundida com mera aplicação das Tecnologias da Informação e Comunicação (TICs) " (Soares, 2011, p.13). Mas o autor observa que este campo que une a educação e a comunicação não se resume às, mas a escola se apresenta como um ambiente privilegiado para as experiências, possibilita o acesso, apresenta ferramentas.

Todavia, com o imperativo da suspensão das aulas presenciais, devido à pandemia, o espaço escolar deixou de ser frequentado, as turmas escolares foram impedidas de se reunirem em uma mesmo espaço físico, e assim, muitos estudantes se distanciaram dos processos formativos que a escola proporcionava. Kaplún (2011) observa a importância pedagógica que a escola exerce de oferecer espaço de socialização e interações grupais. As propostas apresentadas pela pesquisa também se apresentam como alternativa para os estudantes interagirem e partilharem suas narrativas neste período de isolamento social.

Ao se referir à cultura digital e a relação da educomunicação, Aparici (2014) observa que estamos em uma fase de transição entre o analógico e o digital, e que este processo está apenas no começo. Tendo como referência o contexto socioeconômico do país e a crise sanitária potencializada pela pandemia da covid-19 e pela falta de atuação efetiva do poder público, o processo de participação ativa no universo virtual ainda tem muitos passos a serem dados. A inclusão digital ainda será pauta na relação dos desafios da educação por muito tempo.

\section{Considerações Finais}

A pesquisa "Educomunicação socioambiental - narrativas da periferia" destaca que o desafio para a inserção da comunidade escolar no universo digital é grande, encontra entraves nas questões econômicas de acesso à internet, aquisição de equipamentos celulares e computadores. A realização das ações no campo da educomunicação apontou o quanto os estudantes estão ansiosos em participar de propostas integradoras, diferenciadas que possibilitam a expressão dos pontos de vista e que motivem à criatividade. Os murais educomunicativos e a oficina de foto e vídeo, que resultou na exposição do varal de fotos, foram exemplos de propostas com aceitação positiva. 
O modelo de educação bancária, de transmissão de conhecimento, tão combatido por Freire (2019) já não é bemvindo entre crianças e adolescentes que esperam que a escola dialogue com seus anseios e aspirações. Isso não quer dizer que a escola tem que virar um parque de diversões, mas fazer a educação ser mais divertida, mais de acordo com a realidade dos estudantes possibilita que a aprendizagem seja significativa. Martìn-Barbero (2014, p.11) afirma que a escola tem o poder de transforma o cotidiano das pessoas no campo social e cultural, por isso, esta deve ser o espaço para o desenvolvimento da "inteligência coletiva e das biografias coletivas".

Todavia, a pesquisa destaca a urgente necessidade de ações políticas e sociais que possibilitem aos estudantes o acesso às informações virtuais, que possibilitem aquisição de tecnologias da informação, para que a inclusão digital aconteça, e meninos e meninas possam usufruir do direito à educação e à comunicação de forma democrática. Palfrey e Gasser (2011) apontam como nativos digitais todos que nasceram depois de 1980, período que as tecnologias digitais passaram a fazer parte da população mundial. Contudo, neste contexto pandêmico que acentuou as desigualdades sociais, as crianças e jovens que vivem fora deste universo de aulas online não podem ser considerados nativos, e sim excluídos digitais.

Freire $(2020 ; 1999)$ destaca a importância da educação para que as pessoas não recebam comunicados, e sim, comuniquem suas próprias mensagens, para que a educação seja uma prática para a liberdade. "Liberdade é um conceito central na antropologia de Paulo Freire, em torno do qual ele constrói a sua teoria pedagógica” (SUNG, 2019, p. 288). É este acreditar que a educação tem o poder de libertar que fortalece o preceito de um educar para ser livre. A pesquisa realizada em uma escola da periferia de Cuiabá-MT aponta as ações realizadas no campo da educomunicação como forma de dialogar com crianças e adolescentes, de valorizar suas comunicações, e destaca a urgente necessidade de ações efetivas no campo das políticas públicas e sociais para trazer de volta para o universo da educação formal esta parcela de excluídos, tanto da rotina digital quanto da própria formação que a escola deve oferecer no presencial, pós-pandemia.

A pesquisa aponta que, apesar dos desafios enfrentados com a exclusão digital, ações educomunicativas podem ser apresentadas para realização em conjunto com toda comunidade escolar da Escola Estadual Manoel Cavalcanti Proença, tanto na realidade pandêmica, quanto no retorno às aulas presenciais, uma vez que o universo de ações são múltiplos, como a elaboração de um mural escolar ou oficinas de foto e vídeo, conforme esta ação pesquisadora realizou. Mas pode-se pensar, de acordo com a mobilização dos atores sociais no processo, em elaborar rádio escolar, jornal escolar, gravação de programas comunicativos para compartilhar nas redes sociais, entre outras ações.

O cenário pandêmico da covid-19 destacou o quanto as conexões são importantes, sejam relacionadas as interações interpessoais, às trocas de afetos e realização de encontros presenciais, seja as conexões digitais para que mais pessoas possam ter acesso às informações e trocar saberes via aulas online, reuniões virtuais ou recreações digitais. A pesquisa na escola apresentou-se como uma esperança de que é possível conectar saberes e aprendizagens, apesar de todas as limitações e entraves na educação potencializados no período pandêmico, mas que já faziam parte do cenário da educação brasileira, sobretudo, nas escolas da periferia.

\section{Agradecimentos}

Agradecemos o Instituto Federal de Mato Grosso (IFMT) pelo financiamento do Edital n ${ }^{\circ}$ 52/2020 PROPES/IFMT ao Projeto de Pesquisa do GEAC/PPGEn/IFMT, que possibilitou a realização da ação pesquisadora. Registramos nossa gratidão à Escola Estadual Manoel Cavalcanti Proença por acolher a pesquisa. 
Research, Society and Development, v. 10, n. 12, e460101220674, 2021

(CC BY 4.0) | ISSN 2525-3409 | DOI: http://dx.doi.org/10.33448/rsd-v10i12.20674

\section{Referências}

ABPEDUCOM. (2020) Conceito. Webside Abpeducom. https://abpeducom.org.br/educom/conceito/.

ABL. (2021). Academia Brasileira de Letras disponibiliza a 6. ${ }^{\text {a }}$ edição do Vocabulário Ortográfico da Língua Portuguesa. Academia Brasileira. https://www.academia.org.br/noticias/academia-brasileira-de-letras-disponibiliza-6a-edicao-do-vocabulario-ortografico-da-lingua

Aparici, R. (2014). Introdução: A Educomunicação para além do 2.0. In: Aparici, R. Introdução: A Educomunicação para além do 2.0. Paulinas.

Martín-Barbero, M. (2014). A comunicação na educação. Contexto.

Bauer, F. (2021). Apresentação. In: UNICEF. Cenário da exclusão escolar no Brasil. Um alerta sobre os impactos da COVID-19 na Educação. https://www.unicef.org/brazil/media/14026/file/cenario-da-exclusao-escolar-no-brasil.pdf

Freire, P. (2015). Pedagogia do Oprimido. Paz e Terra.

Freire, P. (1999) Educação como prática de liberdade. Paz e Terra.

Freire, P. (2020). Extensão ou comunicação. Paz e Terra.

Kaplún, M. (2011). Processo educativos e canais de comunicação. In: Citelli, A. O. \& Costa, M. C. C. (Org) Educomunicação: construindo uma nova área de conhecimento. São Paulo: Paulinas.

Legrand, L. (2010) Célestin Freinet. Fundação Joaquim Nabuco, Editora Massangana.

Machado, E. S. (2007). Educomunicação transforma escola em polo de reflexão e diálogo. NCE/USP.

Orozco Gomez, G. (2014). Educomunicação: recepção midiática, aprendizagens e cidadania. Paulinas.

Panfley, J. \& Gasser, U. (2011). Nascidos na Era Digital. Grupo A.

Soares, I. de O. (2011) Educomunicação: o conceito, o profissional, a aplicação: contribuições para a reforma do ensino médio. Paulinas.

Stake, R. E. (1999). Investigación con estudio de casos. Madrid: Morata.

Sung, J. M. (2019) Liberdade. In: Streck, R. D., Redin, E; \& Zitkoski, J. J. (Orgs). Dicionário Paulo Freire. Autêntica.

Unicef. (2020). Cenário da exclusão escolar no Brasil. Um alerta sobre os impactos da COVID-19 na Educação. https://www.unicef.org/brazil/media/14026/file/cenario-da-exclusao-escolar-no-brasil.pdf.

Unicef. (2021). Dois terços das crianças em idade escolar no mundo não têm acesso à internet em casa, diz novo relatório do UNICEF-ITU. https://www.unicef.org/brazil/comunicados-de-imprensa/dois-tercos-das-criancas-em-idade-escolar-no-mundo-nao-tem-acesso-a-internet.

Yin, R. K. (2001). Estudo de caso: planejamento e métodos. Bookman.

Yin, R.K. (2015). O estudo de caso. Bookman. 